\title{
Long-term lamivudine treatment of children with chronic hepatitis B: durability of therapeutic responses and safety
}

\author{
M. M. Jonas, ${ }^{1}$ N. R. Little, ${ }^{2}$ S. D. Gardner ${ }^{2}$ and Members of the International Pediatric \\ Lamivudine Investigator Group* ${ }^{1}$ Division of Gastroenterology, Children's Hospital Boston, Boston, MA; and ${ }^{2}$ GlaxoSmithKline \\ Research and Development, Research Triangle Park, NC, USA
}

Received November 2006; accepted for publication January 2007

SUMMARY. Lamivudine has been demonstrated safe and efficacious in the short term in a large cohort of children with chronic hepatitis $\mathrm{B}(\mathrm{CHB})$, but optimal duration of treatment has not been elucidated and limited data on the safety of long-term lamivudine administration have been reported. In addition, the durability of favourable therapeutic outcomes after lamivudine therapy in children has not been well characterized. The aim of this study was to examine the safety of lamivudine and the durability of clinical responses in a group of children who received up to 3 years of treatment for CHB. One hundred and fiftyone children from centres in nine countries who had previously received lamivudine in a large prospective trial were enrolled. During the first year, children had been randomized to either lamivudine or placebo treatment. Subsequently, in a separate extension study, those who remained hepatitis $\mathrm{B}$ e antigen ( $\mathrm{HBeAg}$ ) positive were given lamivudine for up to 2 years and those who were HBeAg negative were observed for additional 2 years. Results of these studies have been previously reported. In this study, these children were followed for 2 additional years. Data gathered from medical record review included weight, height, signs and symptoms of hepatitis, alanine aminotransferase (ALT) levels, serologic markers, hepatitis $B$ virus (HBV) DNA levels and serious adverse events (SAEs). Other pharmacological treatments for CHB were allowed according to the practices of individual investi- gators and were documented. Subjects were divided into two groups for analysis, those who had achieved virological response (VR), defined as HBeAg negative and undetectable HBV DNA by the bDNA assay by the end of the extension study at 3 years, and those who had not. In those who had achieved VR by the end of the extension study, long-term durability of $\mathrm{HBeAg}$ seroconversion was $82 \%$ and $>90 \%$ in those who had received lamivudine for 52 weeks and at least 2 years respectively. This compares to $75 \%$ for those who had achieved seroconversion after placebo. In those who had not achieved VR by the end of the extension study, an additional $11 \%$ did so by the end of the study; they had all received lamivudine in the previous trial, and none had received further treatment during the study. Eight children lost hepatitis B surface antigen during the study and all had received lamivudine at some point during the previous trials. Evaluation of safety data revealed no SAEs related to lamivudine. There was no effect of treatment on weight or height $z$ scores. Clinically benign ALT flares (>10 times normal) were seen in $2 \%$ of children. Favourable outcomes from lamivudine treatment of $\mathrm{CHB}$ in children are maintained for at least several years after completion of treatment. Up to 3 years of lamivudine treatment is safe in children.

Keywords: adolescent, child, hepatitis B, lamivudine, treatment.
Abbreviations: ALT, alanine aminotransferase; anti-HBe, hepatitis B e antibody; CHB, chronic hepatitis B; HBeAg, hepatitis B e antigen; HBsAg, hepatitis B surface antigen; HBV, hepatitis B virus; HCC, hepatocellular carcinoma; PCR, polymerase chain reaction; SAEs, serious adverse events; ULN, upper limit of normal; VR, virological response.

Correspondence: Maureen M. Jonas MD, Division of Gastroenterology, Children's Hospital Boston, 300 Longwood Avenue, Boston, MA 02115, USA. E-mail: maureen.jonas@childrens.harvard.edu

*See Appendix.

\section{INTRODUCTION}

Despite the availability of a safe and highly effective vaccine, hepatitis $\mathrm{B}$ virus (HBV) infection remains a global health problem. Even in countries where infant and childhood immunization is recommended, there are still new cases each year. These cases occur in high-risk subgroups, such as i.v. drug users and homosexual men, as well as in communities with large numbers of immigrants from areas of the world where HBV is still highly endemic. It is in this latter group that most new childhood infections are found, either 
in the immigrant children themselves, children born to immigrant women who are infected, or children who acquire HBV by horizontal transmission within these households.

Chronic hepatitis B (CHB) in children is most often asymptomatic and most children with the infection are clinically well and develop normally. A small number have significant liver disease during childhood or adolescence. However, serious complications such as cirrhosis or hepatocellular carcinoma (HCC) later in life may be expected in approximately $25 \%$ of individuals who acquired infection during infancy or childhood [1]. For this reason, treatment of CHB infection is indicated in some children.

The safety and efficacy of lamivudine for 1 year in children 2 years of age or older has been established [2]. In addition, further serologic and virologic responses (VR), such as hepatitis B e antigen ( $\mathrm{HBe} A g$ ) seroconversion and undetectable HBV DNA levels, have been reported in children on long-term therapy with 2 additional years of treatment [3]. Lamivudine-associated responses have shown durability comparable with those observed in subjects who underwent spontaneous seroconversion during placebo treatment [3]. This study was undertaken to obtain additional clinical information on children who had undergone extended lamivudine therapy in previous studies. In particular, this study was designed to collect information on the natural history of $\mathrm{CHB}$ in children during and following lamivudine therapy, as well as relevant long-term safety data in this group.

\section{SUBJECTS AND METHODS}

This was a multicenter study conducted at 21 centres in the United States, Canada, Europe and South America. The cohort for this study originally participated in a 1-year randomized, placebo-controlled trial of lamivudine for 52 weeks [2], after which, based on their $\mathrm{HBeAg}$ response at week 48, subjects were enrolled in an additional extension study and stratified to either treatment with lamivudine or observation for 2 additional years [3]. All subjects who had participated in the extension study were considered eligible for this study. Subjects could receive continued treatment with lamivudine or another agent for HBV at the discretion of the individual investigators. Because the children had been observed for 3 years on the first two studies, and an additional 2 years in the current study [Month 12 (Year 4) and Month 24 (Year 5)], a total of 5 years of follow-up is provided.

Data recorded for this study were based on retrospective review of medical records for the 2 years following completion of the extension study. Baseline demographic information was recorded from the last visit in the previous extension study. All measurements were collected from the visits closest to each scheduled medical record review, but windows of up to 6 months between visits and record reviews were allowed. Signs and symptoms of CHB were noted.
Biochemical and virologic data included serum alanine aminotransferase (ALT) levels, HBV DNA levels, HBeAg, hepatitis B e antibody (anti-HBe), and hepatitis B surface antigen (HBsAg) results. Pharmacologic treatment for $\mathrm{CHB}$ was documented. Serious adverse events (SAEs) and the proportion of subjects with abnormal laboratory values for ALT and total bilirubin were summarized. NonSAEs information was not collected.

In the previous studies, HBV DNA was determined using a bDNA assay (Bayer Quantiplex Version 1, lower limit of detection $0.7 \mathrm{mEq} / \mathrm{mL}$ ) performed at a central laboratory. In this study, the participating sites used locally available HBV DNA assays. A polymerase chain reaction (PCR) based assay was used for $70 \%$ of the subjects at month 12 and for $79 \%$ of the subjects at month 24 . The use of the more sensitive PCRbased assays makes comparison across the studies somewhat problematic, but does provide an assessment of HBV DNA status at the long-term time points of this study.

\section{DATA ANALYSIS}

The population analysed was the modified intent-to-treat which consisted of all subjects who participated without premature discontinuation from the 2 year extension study. This study was an observational study, during which subjects may have taken lamivudine or other anti-HBV treatment for varying lengths of time. Biochemical, serologic, virologic and safety data are provided descriptively. Because of the nature of this study, no formal statistical testing was performed.

At the completion of the 1-year original randomized placebo-controlled trial, subjects had been assigned in the extension study to either stratum A for continued lamivudine treatment if still $\mathrm{HBeAg}$ positive, or stratum B for notreatment observation if $\mathrm{HBeAg}$ negative. For the analyses of the present study, subjects were grouped by their previous stratum assignment and by the treatment (either lamivudine or placebo) they had received during the original controlled trial (Fig. 1).

Efficacy measures included HBeAg loss or seroconversion, undetectable HBV DNA, ALT normalization and HBsAg loss or seroconversion at months 12 and 24 of this study. These were summarized for subjects with and without VR at the end of the previous extension study.

\section{RESULTS}

Two hundred and sixty subjects were eligible to enroll in the current study. Of these, 151 (58\%) enrolled, 117 from stratum A and 34 from stratum B. The strata were further divided according to the previous treatment group of the subjects during the initial randomized, placebo-controlled trial (Fig. 1). The breakdown into groups and demographic characteristics of the study population are shown in Table 1. Six subjects withdrew from this study; five were lost to 


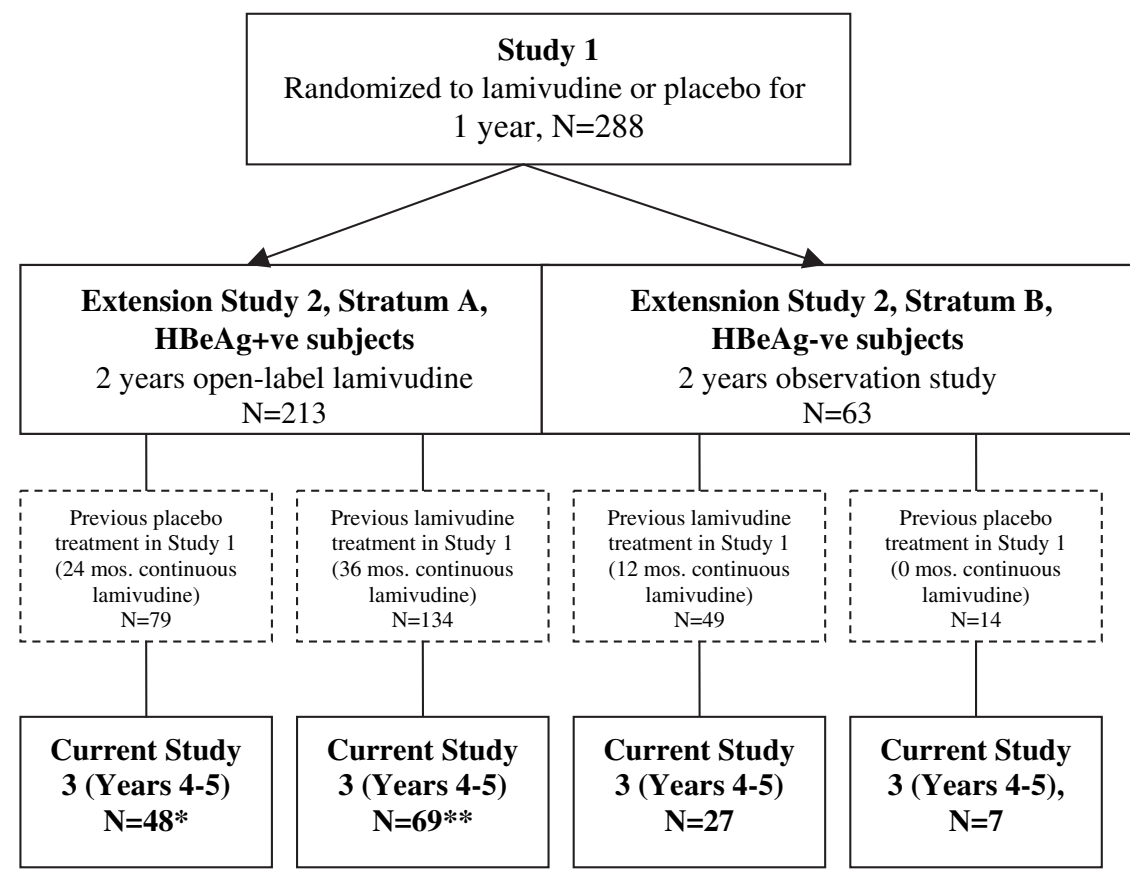

Fig. 1 Origin of subjects for this study according to treatment in original randomized and subsequent open-label lamivudine trials. ${ }^{*} 7 / 48$ received additional therapy during 2-year follow-up in study 3 (lamivudine [3], interferon and lamivudine [1], or adefovir dipivoxil [3]. $* * 9 / 69$ received additional therapy during 2-year follow-up in study 3 (lamivudine [7], or adefovir dipivoxil [2].

Table 1 Demographic characteristics of the study population

\begin{tabular}{lllll}
\hline & \multicolumn{2}{l}{ Previous Strata Treatment Group } & \\
\cline { 2 - 5 } & $\begin{array}{l}\text { Previous stratum } \\
\text { A placebo } \\
n=48\end{array}$ & $\begin{array}{l}\text { Previous stratum } \\
\text { A lamivudine } \\
n=69\end{array}$ & $\begin{array}{l}\text { Previous stratum } \\
\text { B placebo } \\
n=7\end{array}$ & $\begin{array}{l}\text { Previous stratum } \\
\text { B lamivudine } \\
n=27\end{array}$ \\
\hline $\begin{array}{l}\text { Age (years) [median (range) } \\
\text { Gender } n \text { (\%) }\end{array}$ & $10.5(5-21)$ & $13.0(6-22)$ & $16.0(9-19)$ & $11.0(3-19)$ \\
Female & $17(35)$ & $31(45)$ & $1(14)$ & $5(19)$ \\
Male & $31(65)$ & $38(55)$ & $6(86)$ & $22(81)$ \\
Ethnic origin $n(\%)$ & $28(58)$ & $47(68)$ & $7(100)$ & $24(89)$ \\
White & $12(25)$ & $14(20)$ & 0 & $2(7)$ \\
Asian/Oriental & $5(10)$ & $4(6)$ & 0 & 0 \\
Black & $2(4)$ & $4(6)$ & 0 & 0 \\
Hispanic & $1(2)$ & 0 & 0 & $1(4)$ \\
Other & & & \\
\hline
\end{tabular}

follow-up and one withdrew because the investigator thought that the subject's participation was no longer necessary after seroconversion.

\section{Subjects with VR at the end of the extension study}

Sixty-four subjects achieved VR by the end of the extension study (i.e., 2 or 3 years of lamivudine, depending on treatment assignment during the first year controlled study). Data from the next 2 years of observation in the present study (months 12 and 24) for this group are shown in Table 2. The durability of $\mathrm{HBeAg}$ seroconversion with no lamivudine therapy after a total of 4 years of observation was $75 \%(3 / 4)$. In children who had seroconverted after only 52 weeks of lamivudine, it was $82 \%(9 / 11)$, and in those who had received at least 2 years of lamivudine, durability was $>90 \%(11 / 12$ for the previous placebo arm and $16 / 17$ for the previous lamivudine arm). Of the 27 subjects from stratum A with $\mathrm{HBeAg}$ seroconversion at month 24, HBV DNA was undetectable in eight subjects, detectable in seven subjects and unavailable in 12 subjects. All seven subjects with detectable HBV DNA had low virus levels as measured by the local assays. Of the 12 subjects from stratum B with HBeAg seroconversion at month 24, HBV DNA was undetectable in three subjects, detectable in six, and unavailable in three. All six subjects with detectable HBV DNA had low virus levels with the exception of one subject who had an HBV DNA level of $2 \times 10^{5}$ copies $/ \mathrm{mL}$. 
Table 2 Efficacy endpoints at months 12 and 24 in children who achieved VR ${ }^{*}$ at the end of the extension study

\begin{tabular}{|c|c|c|c|c|}
\hline & \multicolumn{4}{|c|}{ Previous Strata Treatment Group } \\
\hline & $\begin{array}{l}\text { Previous stratum } \\
\text { A placebo } \\
n=16\end{array}$ & $\begin{array}{l}\text { Previous stratum } \\
\text { A lamivudine } \\
n=21\end{array}$ & $\begin{array}{l}\text { Previous stratum } \\
\text { B placebo } \\
n=6\end{array}$ & $\begin{array}{l}\text { Previous stratum } \\
\text { B lamivudine } \\
n=21\end{array}$ \\
\hline \multicolumn{5}{|c|}{ HBeAg seroconversion } \\
\hline Month $12 n / \mathrm{N}$ & $10 / 11(91)$ & $16 / 17(94)$ & $3 / 3(100)$ & $14 / 14(100)$ \\
\hline Month $24 n / \mathrm{N}$ & $11 / 12(92)$ & $16 / 17(94)$ & $3 / 4(75)$ & $9 / 11(82)$ \\
\hline \multicolumn{5}{|l|}{ ALT normalization } \\
\hline Month $12 n / \mathrm{N}$ & $11 / 14(79)$ & $13 / 18(72)$ & $2 / 5(40)$ & $18 / 21(86)$ \\
\hline Month $24 n / \mathrm{N}$ & $13 / 16(81)$ & $15 / 19(79)$ & $2 / 6(33)$ & $16 / 19(84)$ \\
\hline \multicolumn{5}{|l|}{ HBsAg loss } \\
\hline Month $12 \mathrm{n} / \mathrm{N}$ & $0 / 13$ & $2 / 17(12)$ & $0 / 4$ & $4 / 17(24)$ \\
\hline Month $24 n / \mathrm{N}$ & $0 / 16$ & $5 / 20(25)$ & $0 / 5$ & $3 / 17(18)$ \\
\hline \multicolumn{5}{|c|}{ HBsAg seroconversion } \\
\hline Month $12 n / \mathrm{N}$ & $0 / 13$ & $1 / 17(6)$ & $0 / 4$ & $3 / 16(19)$ \\
\hline Month $24 n / \mathrm{N}$ & $0 / 16$ & $3 / 19(16)$ & $0 / 5$ & $2 / 16(13)$ \\
\hline
\end{tabular}

*Defined as loss of HBeAg and undetectable HBV DNA by the bDNA assay. Values in parentheses are indicated as percentages.

This subject had received lamivudine only in the initial controlled trial.

A high proportion of those who had received lamivudine in previous trials maintained normal ALT levels during the 2 years of subsequent observation in both strata $A$ and $B$.

In stratum $A$, none of the previous placebo subjects and $25 \%(5 / 20)$ of previous lamivudine subjects had HBsAg loss after 2 years of observation in this study. In stratum B, none of the previous placebo subjects and $18 \%$ (3/17) of previous lamivudine subjects had HBsAg loss after 2 years of observation. A similar pattern was observed for HBsAg seroconversion.

\section{Subjects without VR at the end of the extension study}

Eighty-seven subjects did not achieve VR at the end of the extension study (Table 3). After 12 months of observation in this study, four of $70(6 \%)$ subjects with available data had

Table 3 Efficacy endpoints at months 12 and 24 in children who had not achieved VR ${ }^{*}$ at the end of the extension study

\begin{tabular}{|c|c|c|c|c|}
\hline & \multicolumn{4}{|c|}{ Previous Strata Treatment Group } \\
\hline & $\begin{array}{l}\text { Previous stratum } \\
\text { A placebo } \\
n=32\end{array}$ & $\begin{array}{l}\text { Previous stratum } \\
\text { A lamivudine } \\
n=48\end{array}$ & $\begin{array}{l}\text { Previous stratum } \\
\text { B placebo } \\
n=1\end{array}$ & $\begin{array}{l}\text { Previous stratum } \\
\text { B lamivudine } \\
n=6\end{array}$ \\
\hline \multicolumn{5}{|l|}{ Virologic response } \\
\hline Month $12 n / \mathrm{N}$ & $1 / 26(4)$ & $3 / 41(7)$ & $0 / 1$ & $0 / 2$ \\
\hline Month $24 n / \mathrm{N}$ & $4 / 22(18)$ & $3 / 39(8)$ & $0 / 1$ & $0 / 3$ \\
\hline \multicolumn{5}{|c|}{ HBeAg seroconversion } \\
\hline Month $12 n / \mathrm{N}$ & $3 / 27(11)$ & $7 / 43(16)$ & 1/1 (100) & $5 / 5(100)$ \\
\hline Month $24 n / \mathrm{N}$ & $4 / 21(19)$ & $9 / 42(21)$ & $1 / 1(100)$ & $3 / 3(100)$ \\
\hline \multicolumn{5}{|l|}{ ALT normalization } \\
\hline Month $24 n / \mathrm{N}$ & $10 / 28(36)$ & $11 / 47(23)$ & $0 / 1$ & $5 / 5(100)$ \\
\hline Month $24 n / \mathrm{N}$ & $16 / 28(57)$ & $15 / 46(33)$ & 1/1 (100) & $5 / 6(83)$ \\
\hline \multicolumn{5}{|l|}{ HBsAg loss } \\
\hline Month $12 n / \mathrm{N}$ & $1 / 19(5)$ & $1 / 38(3)$ & $0 / 1$ & $0 / 5$ \\
\hline Month $24 n / \mathrm{N}$ & $1 / 21(5)$ & $0 / 41$ & $0 / 1$ & $0 / 6$ \\
\hline \multicolumn{5}{|c|}{ HBsAg seroconversion } \\
\hline Month $12 n / \mathrm{N}$ & $0 / 19$ & $0 / 38$ & $0 / 1$ & $0 / 5$ \\
\hline Month $24 n / \mathrm{N}$ & $0 / 21$ & $0 / 41$ & $0 / 1$ & $0 / 6$ \\
\hline
\end{tabular}

*Defined as loss of HBeAg and undetectable HBV DNA by the bDNA assay. Values in parentheses are indicated as percentages. 
achieved VR. After 24 months of observation, seven of 65 (11\%) subjects with available data had achieved VR. All of these were in stratum A, meaning that they had all received lamivudine during the extension study, and were not in the observation arm. None of these children who eventually achieved VR received additional HBV treatment during this study. At month 24, HBeAg seroconversion in stratum A was $20 \%$ (13/63); all four subjects in stratum B had HBeAg seroconversion at this time point.

\section{Additional HBV treatment during this 2 year follow-up}

During this observational study, a total of 16 subjects received additional therapy for $\mathrm{CHB}$ at the discretion of the investigator. Additional therapy consisted of continuation or re-initiation of lamivudine $(11 / 16)$, change to adefovir dipivoxil $(5 / 16)$, or a course of interferon $(1 / 16)$ (this subject took both lamivudine and interferon). Fourteen of the 16 were $\mathrm{HBsAg}$ positive, $\mathrm{HBeAg}$ positive prior to this additional therapy and remained so at the end of this study. Two were HBsAg positive, HBeAg negative prior to this additional therapy and remained so at the end of the 2 years of observation.

\section{Safety}

There were no deaths or pregnancies during this study. One SAE was reported, a case of pharyngitis in a 10-year-old child, judged by the investigator to be unrelated to prior study medication use. This subject did not receive additional treatment for CHB during this study. Summary statistics for height and weight $z$ scores are shown in Table 4. Baseline $z$ scores were calculated from data collected before the initial lamivudine or placebo treatment. The mean and median changes from baseline, for both weight and height, in subjects who had been treated with long-term lamivudine, were clinically insignificant, indicating no obvious effect on weight or growth.

The prevalence of abnormal serum ALT and bilirubin values, as well as defined ALT elevations, are reported in Table 5 for all subjects. The highest ALT value recorded during the observational period was used to categorize the elevations. Any elevation of ALT was noted in 36 of 117 (31\%) stratum A subjects, compared with two of 34 (6\%) stratum B subjects. Of the 36 subjects in stratum A with an ALT elevation $>2$ times upper limit of normal (ULN), three $(3 / 117,3 \%)$ had a severe ALT elevation $(>10 \times \mathrm{ULN})$ compared with none in stratum B. None of the ALT elevations occurred in association with HBeAg seroconversion.

These same parameters are reported in Table 6 for subjects who achieved VR at the end of the extension study. Any elevation of ALT was noted in four of $37(11 \%)$ stratum A subjects, compared with one of $27(4 \%)$ stratum B subjects. Of the four subjects in stratum A with an ALT elevation, two had mild elevations and two had moderate elevations.
Two had become HBeAg positive by month 12 of this study (one in previous lamivudine and one in previous placebo group) and had high levels of HBV DNA $\left(>7 \times 10^{6}\right.$ copies/mL; the other two remained $\mathrm{HBeAg}$ negative through month 24 and had low levels of HBV DNA ( $81 \mathrm{MEQ} / \mathrm{mL}$ by bDNA assay and 1140 copies/mL by PCR). One subject in stratum $\mathrm{B}$ who had received no lamivudine in any of the prior studies had a mild ALT elevation. This subject was HBeAg negative, anti-HBe positive and had undetectable levels of HBV DNA at month 24 by PCR.

\section{DISCUSSION}

At the present time, only $\alpha$-interferon and lamivudine are licensed for use in children with $\mathrm{CHB}$. The primary benefit of $\alpha$-interferon in this setting is the fixed duration of therapy. However, $\alpha$-interferon is associated with significant side effects, including derangements of weight gain and growth and requires parenteral administration. Lamivudine, a safe and well-tolerated nucleoside analogue, has proven more effective than placebo in inducing desired therapeutic outcomes in children with HBeAg positive $\mathrm{CHB}$ and abnormal ALT. Factors associated with response to lamivudine in children include degree of pretreatment ALT elevation and histological severity of chronic hepatitis, but not age, race, body weight or body mass index [4]. Long-term lamivudine therapy is associated with virologic, biochemical and histological benefits in adults and has been found to be safe [5-9]. However, in children, the optimal duration of therapy and the safety of long-term use of this agent have not been determined. This study is a further 2-year follow-up of children who had received up to 3 years of continuous lamivudine treatment in previous clinical trials. It was performed to collect additional information regarding durability of efficacy and safety in this population.

This study demonstrates that important serological outcomes, such as HBeAg seroconversion, are usually durable in children who achieve them while being treated with lamivudine, up to 4 years after therapy is discontinued. In addition, HBsAg loss and seroconversion, which occurs very rarely in the untreated natural history of $\mathrm{CHB}$, was seen in children who received lamivudine for 1-3 years. Our findings are consistent with a recent study in Korean children where long-term treatment with lamivudine led to significant improvement in the seroconversion rates of HBeAg and HBsAg [10]. Results of several other small studies of children receiving long-term lamivudine have, however, reported low rates of $\mathrm{HBeAg}$ seroconversion and no clearance of HBsAg [11,12]. No serious toxicity was observed in the children.

Methodological limitations of this study include the retrospective design and not all children who participated in the previous randomized and open-label therapy trials were enrolled. The latter limitation is because investigators at some sites chose not to participate and not every 
Table 4 Weight for age and height for age z-scores at baseline and at months 12 and 24 of observation (before either lamivudine or placebo treatment)

\begin{tabular}{|c|c|c|c|c|}
\hline & \multicolumn{4}{|c|}{ Previous Strata Treatment Group } \\
\hline & $\begin{array}{l}\text { Previous stratum } \\
\text { A placebo } \\
n=48\end{array}$ & $\begin{array}{l}\text { Previous stratum } \\
\text { A lamivudine } \\
n=69\end{array}$ & $\begin{array}{l}\text { Previous stratum } \\
\text { B placebo } \\
n=7\end{array}$ & $\begin{array}{l}\text { Previous stratum } \\
\text { B lamivudine } \\
n=27\end{array}$ \\
\hline \multicolumn{5}{|c|}{ Weight $z$-scores } \\
\hline \multicolumn{5}{|l|}{ Baseline } \\
\hline$n$ & 47 & 69 & 7 & 27 \\
\hline Median & 0.04 & -0.13 & -0.41 & 0.02 \\
\hline Range & -4.06 to 3.46$)$ & -3.41 to 2.32 & -1.97 to 0.56 & -2.13 to 9.07 \\
\hline \multicolumn{5}{|l|}{ Month 12} \\
\hline$n$ & 36 & 56 & 6 & 25 \\
\hline Median & -0.02 & -0.24 & 0.10 & -0.26 \\
\hline Range & -4.29 to 3.05 & -4.04 to 2.20 & -1.58 to 0.79 & -2.42 to 3.33 \\
\hline \multicolumn{5}{|c|}{ Change from baseline } \\
\hline$n$ & 35 & 56 & 6 & 25 \\
\hline Median & -0.19 & -0.13 & 0.33 & -0.34 \\
\hline Range & -1.45 to 2.42 & -2.00 to 2.24 & $0.23-1.56$ & -5.74 to 0.64 \\
\hline \multicolumn{5}{|l|}{ Month 24} \\
\hline$n$ & 35 & 57 & 7 & 21 \\
\hline Median & -0.57 & -0.29 & 0.16 & -0.40 \\
\hline Range & -2.51 to 2.01 & -3.91 to 1.98 & -1.10 to 1.38 & -2.33 to 3.13 \\
\hline \multicolumn{5}{|c|}{ Change from baseline } \\
\hline$n$ & 34 & 57 & 7 & 21 \\
\hline Median & -0.32 & -0.12 & 0.87 & -0.57 \\
\hline Range & -1.40 to 1.98 & -1.62 to 2.45 & $0.05-1.89$ & -5.94 to 1.31 \\
\hline \multicolumn{5}{|c|}{ Height $z$-scores } \\
\hline \multicolumn{5}{|l|}{ Baseline } \\
\hline$n$ & 47 & 69 & 7 & 26 \\
\hline Median & -0.27 & -0.05 & -0.96 & -0.26 \\
\hline Range & -2.18 to 8.58 & -2.87 to 9.71 & -1.52 to 0.68 & -2.10 to 1.54 \\
\hline \multicolumn{5}{|l|}{ Month 12} \\
\hline$n$ & 36 & 56 & 6 & 24 \\
\hline Median & -0.45 & -0.25 & 0.03 & -0.14 \\
\hline Range & -2.95 to 2.10 & -4.39 to 2.86 & -1.15 to 1.35 & -2.23 to 7.12 \\
\hline \multicolumn{5}{|c|}{ Change from baseline } \\
\hline$n$ & 35 & 56 & 6 & 23 \\
\hline Median & -0.09 & -0.16 & 0.49 & -0.20 \\
\hline Range & -1.60 to 1.99 & -8.91 to 1.73 & $0.20-1.11$ & -2.58 to 1.83 \\
\hline \multicolumn{5}{|l|}{ Month 24} \\
\hline$n$ & 35 & 56 & 6 & 20 \\
\hline Median & -0.62 & -0.13 & 0.11 & 0.04 \\
\hline Range & -2.10 to 2.08 & -4.27 to 3.11 & -1.14 to 1.21 & -2.44 to 5.85 \\
\hline \multicolumn{5}{|c|}{ Change from baseline } \\
\hline$n$ & 34 & 56 & 6 & 19 \\
\hline Median & -0.17 & -0.26 & 0.73 & -0.46 \\
\hline Range & -1.29 to 1.36 & -9.21 to 3.36 & $0.32-2.25$ & -2.31 to 0.90 \\
\hline
\end{tabular}

subject at the participating sites consented to the longterm follow-up. However, there was no obvious selection bias in those who chose to participate and at least $50 \%$ enrolment was achieved from each of the stratified treatment groups.
Assessment of the durability of VR, which includes HBeAg loss and undetectable HBV DNA, is confounded in this study by use of multiple HBV DNA assays with varying sensitivities. Subjects who had undetectable HBV DNA by the bDNA assay used in the earlier studies, then 
Table 5 Alanine aminotransferase (ALT) and bilirubin values outside the normal range at months 12 and 24 and defined ALT elevations

\begin{tabular}{|c|c|c|c|c|}
\hline & \multicolumn{4}{|c|}{ Previous Strata Treatment Group } \\
\hline & $\begin{array}{l}\text { Previous stratum } \\
\text { A placebo } \\
n=48\end{array}$ & $\begin{array}{l}\text { Previous stratum } \\
\text { A lamivudine } \\
n=69\end{array}$ & $\begin{array}{l}\text { Previous stratum } \\
\text { B placebo } \\
n=7\end{array}$ & $\begin{array}{l}\text { Previous stratum } \\
\text { B lamivudine } \\
n=27\end{array}$ \\
\hline \multicolumn{5}{|l|}{ ALT > ULN $n(\%)$} \\
\hline Month 12 & $21 / 42(50)$ & $42 / 66(64)$ & $4 / 6(67)$ & $3 / 26(12)$ \\
\hline Month 24 & $15 / 44(34)$ & $36 / 66(55)$ & $4 / 7(57)$ & $4 / 25(16)$ \\
\hline \multicolumn{5}{|l|}{ Bilirubin > ULN $n(\%)$} \\
\hline Month 12 & $4 / 31(13)$ & $7 / 54(13)$ & $2 / 4(50)$ & $1 / 21(5)$ \\
\hline Month 24 & $3 / 29(10)$ & $11 / 44(25)$ & $2 / 5(40)$ & $1 / 19(5)$ \\
\hline \multicolumn{5}{|l|}{ Defined ALT elevations* } \\
\hline Any elevation $n(\%)$ & $13(27)$ & $23(33)$ & $1(14)$ & $1(4)$ \\
\hline Mild elevation $n(\%)(2 \times \mathrm{ULN}-5 \times \mathrm{ULN})$ & $7(54)$ & $16(70)$ & $1(100)$ & $1(100)$ \\
\hline $\begin{array}{l}\text { Moderate elevation } n(\%) \\
(5 \times \mathrm{ULN} \text { to } \geq 10 \times \mathrm{ULN})\end{array}$ & $4(31)$ & $6(26)$ & 0 & 0 \\
\hline Severe elevation $n(\%)(>10 \times \mathrm{ULN})$ & $2(15)$ & $1(4)$ & 0 & 0 \\
\hline
\end{tabular}

*Highest ALT value at any time during the study.

Table 6 Alanine aminotransferase (ALT) and bilirubin values outside the normal range at months 12 and 24 and defined ALT elevations in subjects who achieved VR at the end of the extension study

\begin{tabular}{|c|c|c|c|c|}
\hline & \multicolumn{4}{|c|}{ Previous Strata Treatment Group } \\
\hline & $\begin{array}{l}\text { Previous stratum } \\
\text { A placebo } \\
n=16\end{array}$ & $\begin{array}{l}\text { Previous stratum } \\
\text { A lamivudine } \\
n=21\end{array}$ & $\begin{array}{l}\text { Previous stratum } \\
\text { B placebo } \\
n=6\end{array}$ & $\begin{array}{l}\text { Previous stratum } \\
\text { B lamivudine } \\
n=21\end{array}$ \\
\hline \multicolumn{5}{|l|}{ ALT > ULN $n(\%)$} \\
\hline Month 12 & $3 / 14(21)$ & $6 / 19(32)$ & $3 / 5(60)$ & $3 / 21(14)$ \\
\hline Month 24 & $3 / 16(19)$ & $5 / 20(25)$ & $4 / 6(67)$ & $3 / 19(16)$ \\
\hline \multicolumn{5}{|l|}{ Bilirubin > ULN $n(\%)$} \\
\hline Month 12 & $1 / 10(10)$ & $5 / 14(36)$ & $1 / 3(33)$ & $1 / 17(6)$ \\
\hline Month 24 & $0 / 10$ & $4 / 10(40)$ & $1 / 4(25)$ & $1 / 14(7)$ \\
\hline \multicolumn{5}{|l|}{ Defined ALT elevations* } \\
\hline Any elevation $n(\%)$ & $2(13)$ & $2(10)$ & $1(17)$ & 0 \\
\hline Mild elevation $(2 \times \mathrm{ULN}-5 \times \mathrm{ULN}) n(\%)$ & $1(50)$ & $1(50)$ & $1(100)$ & 0 \\
\hline Moderate elevation $(5 \times \mathrm{ULN}$ to $\geq 10 \times \mathrm{ULN})$ & $1(50)$ & $1(50)$ & 0 & 0 \\
\hline Severe elevation $(>10 \times \mathrm{ULN}) n(\%)$ & 0 & 0 & 0 & 0 \\
\hline
\end{tabular}

*Highest ALT value at any time point during the study.

found to have very low levels of HBV DNA by PCR-based assays during this 2 year period, would have to be characterized in this study as having lost response, a designation which may not be clinically significant. However, a high proportion of subjects maintained HBeAg seroconversion and ALT normalization within the 2 year observation period, regardless of original treatment assignment or stratum in the long-term treatment trial. This suggests that seroconversion associated with lamivudine treatment is as durable as spontaneous seroconversion in children. The duration of required 'consolidation' treatment, i.e., continuation of lamivudine after HBeAg seroconversion, could not be determined for individual subjects from this study, as treatment was continued for most subjects in the original studies after seroconversion occurred.

Some children with $\mathrm{CHB}$ should be considered for treatment, especially if ALT is persistently abnormal, 
indicating immune activation and the potential for hepatic injury. The duration of viral replication associated with hepatic injury is most likely proportional to the likelihood of complications such as cirrhosis and HCC. Treatment during childhood should be aimed at shortening this time period, as signified by normalization of ALT, disappearance of serum $\mathrm{HBV}$ DNA and $\mathrm{HBeAg}$ seroconversion. Although monitoring for resistance should be considered, as resistance to lamivudine is associated with a very low rate of subsequent therapeutic responses [3,13], lamivudine is a safe and effective option for up to 3 years for the treatment of children with $\mathrm{CHB}$.

\section{APPENDIX}

In addition to the authors, participating members of the International Pediatric Lamivudine Investigator Group include the following: E. M. Alonso, Children's Memorial Hospital, Chicago; F. Alvarez, Hôpital Ste.-Justine, Montreal; J Areias, Hospital General Santo António, Porto, Portugal; I. Badia, Hospital General de Niños, Buenos Aires, Argentina; G. Cordeiro Ferreira, Hospital Fernando da Fonseca, Amadora, Portugal; D. Gremse, University of South Alabama, Mobile; B. Haber, Children's Hospital of Philadelphia, Philadelphia; D. Kelly, Birmingham Children's Hospital, Birmingham, UK; N Manolaki, Agia Sofia Children's Hospital, Athens, Greece; J. Mizerski, John Paul II Hospital, Krakow, Poland; P. Mohan, Children's National Medical Center, Washington, D.C.; J. Molleston, James Whitcomb Riley Hospital for Children, Indianapolis; K. Murray, Children's Hospital and Regional Medical Center, Seattle; I. Pó, Hospital Dona Estefânia, Lisbon, Portugal; G. Porta, Instituto da Criança Prof. Pedro de Alcântara, São Paolo, Brazil; N. Rodriguez-Baez, Children's Medical Center of Dallas, Dallas; K. Schwarz, Johns Hopkins Hospital, Baltimore; E. Sokal, Clinique Universitaire St-Luc, Brussells, Belgium; W. Sluzewski, Klinica Obserwacyjno-Zakazna, Poznan, Poland; M. Woynarowski, Instytut Pomnik-Centrum Zdrowia Dziecka, Warsaw, Poland.

\section{REFERENCES}

1 Hoofnagle JH, Di Bisceglie AM. The treatment of chronic viral hepatitis. N Engl J Med 1997; 336: 247-256.

2 Jonas MM, Kelly DA, Mizerski J et al. Clinical trial of lamivudine in children with chronic hepatitis B. $N$ Engl J Med 2002; 346: 1706-1713.

3 Sokal EM, Kelly DA, Mizerski J et al. Long-term lamivudine therapy for children with HBeAg-positive chronic hepatitis B. Hepatology 2006; 43: 225-232.

4 Hom X, Little NR, Gardner SD, Jonas MM. Predictors of virologic response to lamivudine treatment in children with chronic hepatitis B. Pediatr Infect Dis J 2004; 23: 441-445.

5 Liaw Y-F, Leung NWY, Chang T-T et al. Effects of extended lamivudine therapy in Asian patients with chronic hepatitis B. Gastroenterology 2000; 119: 172-180.

6 Lau DT-Y, Khokhar MF, Doo E et al. Long-term therapy of chronic hepatitis B with lamivudine. Hepatology 2000; 32: $828-834$.

7 Leung NWY, Lai C-L, Chang T-T et al. Extended lamivudine treatment in patients with chronic hepatitis B enhances hepatitis $\mathrm{B}$ e antigen seroconversion rates: results after 3 years of therapy. Hepatology 2001; 33: 1527-1532.

8 Dienstag JL, Cianciara J, Karayalcin S et al. Durability of serologic response after lamivudine treatment of chronic hepatitis B. Hepatology 2003; 37: 748-755.

9 Dienstag JL, Goldin RD, Heathcote EJ et al. Histological outcome during long-term lamivudine therapy. Gastroenterology 2003; 124(1): 105-117.

10 Choe B-H, Lee JY, Jang YC et al. Long-term therapeutic efficacy of lamivudine compared with interferon- $\alpha$ in children with chronic hepatitis B: the younger the better. JPGN 2007; 44: 92-98.

11 Ozgenc F, Arikan C, Sertoz RY et al. Effect of long-term lamivudine in chronic hepatitis B virus-infected children. Antivir Ther 2004; 9: 729-732.

12 Hartman C, Berkowitz D, Eshach-Adiv O et al. Long-term lamivudine therapy for chronic hepatitis B infection in children unresponsive to interferon. J Pediatr Gastro 2006; 43: 494-498.

13 Liaw Y-F, Chien R-N, Yeh C-T. No benefit to continue lamivudine therapy after emergence of YMDD mutations. Antivir Ther 2004; 9: 257-262. 